\title{
Autoria Feminina na Literatura de Língua Inglesa: Mary Shelley e Frankenstein
}

\author{
Female Authorship in English Language Literature: Mary Shelley and Frankenstein \\ Autoría femenina en la literatura en lengua inglesa: Mary Shelley y Frankenstein
}

Recebido: 08/06/2021 | Revisado: 16/06/2021 | Aceito: 19/06/2021 | Publicado: 23/06/2021

\author{
Daniela Morales Monteiro \\ ORCID: https://orcid.org/0000-0002-7421-5667 \\ Instituto Federal de Educação, Ciência e Tecnologia de Minas Gerais, Brasil \\ E-mail: monteirodani1979@gmail.com \\ Tamires Vieira Pinheiro de Castro \\ ORCID: https://orcid.org/0000-0001-8799-5095 \\ Instituto Federal de Educação, Ciência e Tecnologia de Minas Gerais, Brasil \\ E-mail: ta.mires.castro@hotmail.com
}

\begin{abstract}
Resumo
Este artigo tem como objetivo apresentar uma discussão a respeito das obras de autoria feminina no acervo do PNLD Literário de 2018 e propor uma análise da obra Frankenstein ou O Prometeu moderno (1818) da escritora Mary Shelley, a partir da edição em português pela Zahar, publicada no ano de 2017. Para a realização da pesquisa pretende-se, por meio do aporte teórico da Estética da Recepção, observar as potencialidades da obra para a construção do leitor estético na sala de aula e se o livro possui discurso emancipatório, já que, no ano de 2018, foi incorporado ao catálogo do PNLD - Literário, indicado para as séries do Ensino Médio. Justifica-se a escolha do referido texto (SHELLEY, 2017) por ser de autoria feminina, por ser considerado um clássico universal, por estar presente no PNLD Literário de 2018 e por sua temática ser atual e relevante aos alunos.
\end{abstract}

Palavras-chave: Literatura de autoria feminina; PNLD Literário; Mary Shelley.

\begin{abstract}
This paper aims to present a discussion about the works of female authorship in the collection of PNLD Literary 2018 and propose an analysis of the work Frankenstein or the modern Prometheus (1818) by writer Mary Shelley, from the Portuguese edition by Zahar, published in 2017. In order to carry out this research it is intended, through the theoretical contribution of the Aesthetics of Reception, to observe the potential of the work for the construction of the aesthetic reader in the classroom and if the book has an emancipatory discourse, since, in 2018, it was incorporated into the catalog of PNLD - Literary, indicated for the high school grades. The choice of this text (SHELLEY, 2017) is justified because it is written by women, because it is considered a universal classic, because it is present in the PNLD Literary of 2018 and because its theme is current and relevant to students.
\end{abstract}

Keywords: Female authorship literature; PNLD Literary; Mary Shelley.

\section{Resumen}

Este artículo tiene como objetivo presentar una discusión sobre las obras de autoría femenina en la colección literaria del PNLD de 2018 y proponer un análisis de la obra Frankenstein o The Prometheus Modern (1818) de la escritora Mary Shelley, de la edición portuguesa de Zahar, publicada en el año 2017. Para el propósito de la investigación, se pretende, a través del aporte teórico de la Estética de la Recepción, observar el potencial del trabajo para la construcción del lector estético en el aula y si el libro tiene un discurso emancipatorio, ya que, en el año 2018, se incorporó al PNLD - Catálogo Literario, indicado para grados de bachillerato. La elección del texto referido se justifica (SHELLEY, 2017) porque es de autoría femenina, porque se considera un clásico universal, porque está presente en el PNLD Literario 2018 y porque su temática es actual y relevante para los estudiantes.

Palabras clave: Literatura escrita por mujeres; PNLD literário; Mary Shelley.

\section{Introdução}

A Literatura tem sido potencialmente mais acessível aos alunos e afeta a maneira como os professores veem a aprendizagem de línguas sob uma perspectiva literária. Sobre as vantagens do uso da literatura nas aulas de língua inglesa, (Collie \& Slater, 1987) afirmam que a literatura fornece um contexto rico em que itens lexicais ou sintáticos são tornados mais memoráveis. Ao ler um corpo substancial e contextualizado de texto, os alunos se familiarizam com muitos recursos da linguagem escrita, ampliam e enriquecem suas próprias habilidades de escrita. 
Neste sentido, a literatura se apresenta como veículo fundamental para desenvolver as habilidades linguísticas, aprimorar o conhecimento cultural e proporcionar experiência estética. Além disso, o texto literário também contribui para o desenvolvimento do senso crítico dos alunos.

Sob o prisma da recepção, das formas de apropriação da literatura por seus leitores, (Jauss, 1967), em sua lição inaugural na Universidade de Konstanz, defendeu a renovação da história da literatura, dando a prioridade analítica ao aspecto da recepção sobre os da produção e da representação. Segundo o autor:

"O meu programa para superar a distância entre literatura e história, entre conhecimento histórico e estético, aproveita-se dos resultados de ambas as escolas (o formalismo e o marxismo). Os seus métodos veem o fato literário dentro de um círculo fechado de estética da produção e da representação. Prescindem de uma dimensão da literatura, fundamental, dados o seu caráter estático e a sua função social: a dimensão da sua recepção e os efeitos que ela ocasiona". (Lima 1979, p.11 apud Jauss, 1967, p.37)

Apoiada em (Jauss, Stierle, 1979) afirma que a recepção é sempre o momento de um processo que se inicia pelo "horizonte de expectativa" do leitor e que prossegue no movimento de uma "lógica hermenêutica de pergunta e resposta". Com isso, relaciona a posição do primeiro receptor com os seguintes e assim resgata o potencial de significado da obra, na continuação do diálogo com ela:

“O significado de uma obra literária é apreensível não pela análise isolada da obra, nem pela relação da obra com a realidade, mas tão só pela análise do processo de recepção, em que a obra se expõe, por assim dizer na multiplicidade de seus aspectos.” (Stierle, 1979, p.134).

Neste sentido, a teoria da recepção se concretiza como uma teoria dos pontos de vista relevantes de uma obra, na medida em que envolve cada uma das atividades que se desencadeiam no receptor por meio do texto, desde a simples compreensão até a diversidade das reações por ela provocadas (Jauss, 1979).

O conceito de leitor estético é desenvolvido a partir da estética da recepção, que privilegia a dimensão da leitura e do efeito, pois concebe o texto literário como um fato que não se limita à dimensão estética e também considera a dimensão social. Ademais, toma como objeto de investigação o receptor, nova concepção de leitor, tanto para o conhecimento estético quanto para o conhecimento histórico.

A obra A literatura e a formação do homem, de Antônio Candido (1972), traz reflexões importantes sobre a função humanizadora da literatura e seu caráter educativo e formador:

"Um certo tipo de função psicológica é talvez a primeira coisa que nos ocorre quando pensamos no papel da literatura. A produção e a fruição desta se baseiam numa espécie de necessidade universal de ficção e de fantasia, que decerto é coextensiva ao homem, pois aparece invariavelmente em sua vida, como indivíduo e como grupo, ao lado da satisfação das necessidades mais elementares. (...) Talvez os contos populares, as historietas ilustradas, os romances policiais ou de capa-e-espada, as fitas de cinema, atuem tanto quanto a escola e a família na formação de uma criança e de um adolescente. (2002, p.80)"

Candido (2002, p. 83) afirma que função educativa da literatura é muito mais complexa do que pressupõe um ponto de vista estritamente pedagógico. A própria ação que exerce nas camadas profundas afasta a noção convencional de uma atividade delimitada e dirigida segundo os requisitos das normas vigentes.

Tendo em vista as considerações de Jauss e Candido sobre as múltiplas dimensões do fazer literário é possível verificar que o impacto da leitura na vida do leitor é mais real do que se imagina.

Conforme verificado no trecho em que a criatura Frankenstein tem contato com o mundo das letras e faz referência a clássicos: Os Sofrimentos do Jovem Werther, de Goethe, que permitiu ao ser abominável conhecer os sentimentos individuais, 
a tristeza e o abatimento; Vidas ilustres, de Plutarco, por meio da qual ele aprendeu a apreciar as virtudes e a desprezar os vícios; e, por fim, O paraíso perdido, de John Milton, que o permitiu reconhecer-se definitivamente como um desgraçado.

Observa-se neste trecho que as leituras da criatura possibilitaram que ele tivesse um entendimento mais refinado da natureza humana.

A reflexão sobre o romance epistolar Frankenstein, através da estética da recepção permite aos alunos, para além da obra, conhecerem-se a si mesmos e ao mundo ao seu redor, não obstante, é necessária a atuação de um mediador no encontro do leitor com um texto literário - quando esse leitor está em formação-, para que esta experiência seja significativa e promova o crescimento do indivíduo.

Neste sentido, práticas de ensino que tragam uma reflexão sobre o conhecimento histórico bem como o trabalho com projetos interdisciplinares possibilitam uma diversidade na apresentação dos saberes e uma construção conjunta destes saberes com os alunos exercendo papel de protagonistas no processo de ensino-aprendizagem.

Em consonância com os documentos oficiais que norteiam as práticas de ensino, a Base Nacional Comum Curricular (BNCC) traça em seus objetivos a formação do leitor literário, com especial destaque para o desenvolvimento da fruição, de modo a evidenciar a condição estética desse tipo de leitura e de escrita.

No que tange à função utilitária da literatura, o documento ressalta a dimensão humanizadora, transformadora e mobilizadora da arte, que deve garantir a formação de - um leitor-fruidor, ou seja, um sujeito que seja capaz de adentrar na leitura dos textos, de "desvendar" suas múltiplas camadas de sentido, de responder às suas demandas e de firmar pactos de leitura (Brasil, 2018).

O documento preconiza que, ao Ensino Médio, cabe aprofundar a análise sobre as linguagens e seus funcionamentos, intensificando a perspectiva analítica e crítica da leitura, escuta e produção de textos verbais e multissemióticos. Com isso, alarga as referências estéticas, éticas e políticas que cercam a produção e recepção de discursos, ampliando as possibilidades de fruição, de construção e produção de conhecimentos, de compreensão crítica e intervenção na realidade e de participação social dos jovens, nos âmbitos da cidadania, do trabalho e dos estudos.

É neste sentido que a estética da recepção proposta por Jauss atende às demandas de desenvolver as habilidades de leitura e compreensão de textos literários nos alunos.

\section{Metodologia}

Este estudo apoiou-se na pesquisa bibliográfica como tipo de procedimento para o processo de investigação, que segundo Severino (2007) é aquela que se realiza, a partir do:

“[...] registro disponível, decorrente de pesquisas anteriores, em documentos impressos, como livros, artigos, teses etc. Utilizam-se dados de categorias teóricas já trabalhadas por outros pesquisadores e devidamente registrados. Os textos tornam-se fontes dos temas a serem pesquisados. $\mathrm{O}$ pesquisador trabalha a partir de contribuições dos autores dos estudos analíticos constantes dos textos" (Severino, 2007, p.122).

Para isso, buscamos no Banco de teses da Capes pesquisas realizadas sobre o clássico traçando uma análise da obra Frankenstein ou O Prometeu moderno (1818) da escritora Mary Shelley, a partir da edição em português pela Zahar, publicada no ano de 2017.

Outrossim, buscamos trazer informações sobre o PNLD Literário 2018 para fundamentar a escolha da obra para práticas de ensino de língua inglesa por meio de texto literário, assim como mostrar a relevância do trabalho com a obra em sala de aula.

O estudo dos Parâmetros Nacionais Curriculares (PCNs) e da Base Nacional Comum Curricular (BNCC) revelou que 
a obra está em consonância com os pressupostos estabelecidos para as práticas de ensino em literatura na medida em que apresenta temas atuais para o desenvolvimento do leitor crítico.

Neste sentido, por meio do aporte teórico da Estética da Recepção, buscamos evidenciar as potencialidades da obra para a construção do leitor estético na sala de aula e se o livro possui discurso emancipatório, já que, no ano de 2018, foi incorporado ao catálogo do PNLD - Literário indicado para as séries do Ensino Médio.

\section{PNLD Literário}

O Programa Nacional do Livro e do Material Didático (PNLD) 2018- Literário tem como propósito disponibilizar obras didáticas, pedagógicas e literárias por meio de uma avaliação, para atingir estudantes das redes federais, estaduais, municipais e distrital, e também instituições pertencentes ao Poder Público.

Antes intitulado como Programa Nacional do Livro Didático (PNLD) e Programa Nacional Biblioteca da Escola (PNBE), como órgãos separados, o Decreto no 9.099, de 18 de julho de 2017 unificou as atividades de aquisição e distribuição de livros didáticos e literários. De acordo com o Ministério da Educação, com nova nomenclatura, o Programa Nacional do Livro e do Material Didático - PNLD também teve seu escopo ampliado com a possibilidade de inclusão de outros materiais de apoio à prática educativa para além das obras didáticas e literárias: obras pedagógicas, softwares e jogos educacionais, materiais de reforço e correção de fluxo, materiais de formação e materiais destinados à gestão escolar, entre outros." (Brasil 2017).

O programa atende à educação infantil, anos iniciais do ensino fundamental, anos finais do ensino fundamental e Ensino Médio. Além das séries escolares atendidas, no âmbito do PNLD, também podem ser contemplados estudantes e professores das diversas etapas, da mesma forma que indivíduos específicos da educação básica. (Brasil, 2017). Podemos também encontrar na internet os guias das edições passadas, bem como o do ano de 2018 que será discutido neste artigo. O Guia Digital está disponível para consultas de resenhas das obras dispostas com o objetivo de facilitar a escolha do livro pelo docente.

De acordo com o documento, o livro literário é um importante recurso para a promoção de práticas de leitura literária na escola. É através desta leitura que os alunos podem ter acesso à Literatura e à oportunidade de ampliar seu repertório cultural, ampliar sua compreensão do mundo que os cerca, ter acesso a diferentes pontos de vista e ao potencial transformador e humanizador da Literatura.

Outra novidade que merece destaque é a disponibilização de obras literárias em língua inglesa para o Ensino Médio. A partir desta edição do Programa, professores de língua inglesa poderão dispor desse recurso para suas aulas, ampliando o contato de seus alunos com textos literários escritos nessa língua.

O Programa visa que, a partir da oferta de múltiplas obras literárias para sua seleção, professor e mediador de leitura possam qualificar cada vez mais as práticas de leitura literária e formação de jovens leitores realizados nas escolas e fora delas.

O Guia PNLD de 2018 - Literário cumpre a função essencial de auxiliar no processo de escolha qualificada. As obras literárias que se apresentam no guia, foram avaliadas e aprovadas por uma equipe de especialistas das áreas de Letras e de Educação, sendo num segundo momento selecionadas em nível de escola aquelas que melhor se relacionam com o projeto pedagógico e com os propósitos educacionais de sua rede de ensino.

Contudo, de acordo com Felizardo (2018, p. 42), no PNLD de 2018 foi extinto o edital de chamamento para seleção da universidade, e o Ministério da Educação, de maneira centralizadora, ficou responsável por indicar os profissionais responsáveis por essa análise. Os demais participantes foram escolhidos a partir de um banco de dados do MEC, onde profissionais que tivessem grau de licenciatura pudessem se inscrever. 
A autora ressalta que a mudança no Edital de 2018, no que diz respeito à autonomia de gestores e professores na escolha dos livros a serem usados nas escolas, possibilita a homogeneização dos livros escolhidos em todas as escolas de uma cidade ou estado e os professores, ao contrário do que acontecia anteriormente, ficariam, portanto, totalmente afastados do processo de escolha.

No entanto, o Guia orienta que é preciso considerar, além dos aspectos inerentes ao livro literário, o contexto da escola, o seu Projeto Político, o perfil dos estudantes e as demandas mais emergentes em relação ao trabalho com o texto literário na Educação Infantil, nos Anos Iniciais do Ensino Fundamental e no Ensino Médio.

O Guia também traz as resenhas das obras aprovadas no PNLD 2018 - Literário com o objetivo de apresentar a diversidade de possibilidades que se descortinam a partir delas. Segundo o documento, espera-se que as resenhas possam contribuir para debates e reflexões nas escolas e privilegiem escolhas que considerem os contextos, as singularidades e os participantes desse processo, oportunizando também a inclusão de novas obras no acervo literário das escolas.

No ano de 2018, na categoria Ensino Médio, foram escolhidas 190 obras, das quais, seis (3,15\%) são obras pertencentes à língua inglesa. Os títulos escolhidos foram The War of the Worlds, de H. G. Wells, Frankenstein, de Mary Shelley, The Adventures of Huckleberry Finn, de Mark Twain, Oliver Twist, de Charles Dickens, Pride and Prejudice, de Jane Austen e The Strange Case of Dr. Jekyll and Mr. Hyde, de Robert Louis Stevenson. Das seis obras, apenas duas (1,05\%) são de autoria feminina. Em 2013, no antigo PNBE - Programa Nacional Biblioteca da Escola -Frankenstein em quadrinhos de Mary Shelley, por Taisa Borges está disponível no catálogo na categoria Ensino Médio.

Contudo, conforme o documento (Brasil 2018, p.15), os critérios eliminatórios para escolha das obras empregados enfatizam a avaliação da dimensão estética e literária das mais de mil obras inscritas no PNLD e seu papel na formação de jovens leitores(as), além de respeitar critérios de adequação linguística, de isenção de preconceitos, moralismos ou estereótipos que não contribuem para a experiência estética do(a) jovem leitor(a), bem como a adequação a itens relacionados à inscrição da obra neste Programa.

Neste sentido, escolhemos para desenvolver este estudo, a obra Frankenstein de Mary Shelley para elucidar a presença da autoria feminina, já no século XIX, em textos literários. É possível verificar na obra que a autora foge das temáticas típicas, que caracterizam as obras literárias de autoria feminina da época, definidas por Magalhães (1992) como escritas intencionalmente preocupadas com as questões das mulheres e suas rupturas em relação a sociedade em que vivem.

A leitura e mediação desta obra com alunos do Ensino Médio suscitam reflexões sobre as construções identitárias que são determinadas pelo gênero da autoria, na medida em que observamos o contexto histórico em que foram produzidas, conforme destaca Magalhães (1992, p.152) pelo "denominador simbólico, definido pela forma como a autora, condicionada por elementos fisiológicos, antropológicos, socioeconômicos, culturais, responde aos problemas de produção e de reprodução material e simbólica". Salienta-se que Mary Shelley, revela na obra seu processo criativo e suas vivências de leituras referenciando clássicos como Paraíso perdido, Vidas paralelas e Os sofrimentos do jovem Werther. Segundo Eco (1985), os prefácios elaborados pela escritora e seu marido retomam a ideia de "máscaras", interpostas entre o leitor e o livro, além de fornecerem justificativas à sociedade sobre o porquê das escolhas da escritora na sua produção da literária.

Conforme apontou Colomer (2003), o romance de ficção científica, a exemplo do Frankenstein, aciona o imaginário do jovem leitor, pela especulação do que o mundo poderia ser a partir dos conhecimentos da ciência, assim, revela reflexões sobre o contexto histórico e social em que se insere.

\section{A Obra Frankenstein}

O nome Frankenstein possui uma ligação com a alquimia. A tradução significa Pedra dos Franks ou Pedra dos Francos, pelas quais o antigo povo germânico deu origem à França (Shelley, 2017, p. 14). 
Um fato interessante a ser apontado é que muitas pessoas confundem o nome do criador, Victor Frankenstein, com a criatura.

O motor da história é sem dúvida a desenfreada busca e ansiedade de conhecimento do Dr. Victor Frankenstein, que de personagem principal da trama, passa a um papel secundário na mente e na concepção dos espectadores que empoderam a criatura de uma imagem ficcional tão possante passando a chamá-lo de Frankenstein, não sendo este, no entanto, o nome do monstro, mas sim de seu criador. (de La Roche; Teixeira, 2001, p. 28)

Algumas pessoas podem confundir a criatura com o Victor, talvez pelas adaptações e versões para o cinema. No entanto, na obra, Shelley apenas a denomina como criatura ou monstro. De acordo com Soares (2015, p. 14), “a monstruosidade da Criatura é atribuída pelo homem que vê nela refletida os seus próprios medos, simplesmente por "ser" diferente, ou seja, é considerado incapaz de "fazer parte" da humanidade, de ter espaço".

A edição da Zahar foi traduzida, apresentada e notas escritas por Santiago Nazarian e os anexos foram traduzidos por Bruno Gambarotto. A capa, assim como a contracapa, é dourada com ilustrações de membros do corpo humano em amarelo e cinza, indicando serem partes da criação de Victor Frankenstein. Todas as edições de bolso e comentadas dos clássicos, assim como Frankenstein, são em capa dura, têm ilustrações nas contraguardas. Nessa edição de Frankenstein em edição comentada (Shelley, 2017), é possível observar na contraguarda em amarelo com veias brancas e ao centro tem-se a criatura também em amarelo.

A obra é considerada um clássico por perdurar durante séculos e seus temas nunca se esgotarem. Segundo Eagleton (1997), "assim como uma obra pode ser considerada como filosofia num século, e como literatura no século seguinte, ou viceversa, também pode variar o conceito do público sobre o tipo de escrita considerado como digno de valor" (Eagleton, 1997, p. 17). Ele afirma ainda que qualquer obra pode ser ou deixar de ser literatura, ou seja, irá depender do público para que alcance tal condição. Calvino (1993) elenca alguns critérios a serem observados para que uma obra seja considerada canônica e destacamos:

4. Toda releitura de um clássico é uma leitura de descoberta como a primeira.

5. Toda primeira leitura de um clássico é na realidade uma releitura.

6. Um clássico nunca terminou de dizer aquilo que tinha para dizer.

7. Os clássicos são aqueles livros que chegam até nós trazendo consigo as marcas das leituras que precederam a nossa e atrás de si os traços que deixaram na cultura ou nas culturas que atravessaram (ou mais simplesmente na linguagem ou nos costumes). (Calvino, 1993, p. 11)

Frankenstein é um dos romances de horror mais famosos da história da literatura e um dos mais antigos, que está presente nas mentes de crianças e adultos. Para Santiago Nazarian, "a história parece ter a capacidade eterna de se moldar a diferentes tendências e roupagens, de acordo com a época." (Shelley, 2017).

A obra de Mary Shelley se modificou com o tempo devido às recriações e representações cinematográficas, porém a essência permanece. Conforme Eagleton, "todas as obras literárias, em outras palavras são "reescritas", mesmo que inconscientemente, pelas sociedades que as lêem; na verdade, não há releitura de uma obra que não seja também uma “reescritura". (Eagleton, 1997, p. 19). Dessa forma, a obra sofre influência com o passar dos anos e uma questão que passou despercebida em determinada época, pode ser considerada preconceituosa em outra. Para Bittencourt, "existe uma relação dialógica entre o autor e o leitor da obra, e essa relação possibilita sempre um encontro entre lugares e épocas diferentes" (Bittencourt, 2008, p. 344). Como por exemplo alguns costumes da época podem ser considerados machistas hoje, tal como a cena quando Elizabeth, futura noiva de Victor, é recuperada pela família por sua condição pobre, apesar de ser bonita e loira.

Frankenstein ou o Prometeu Moderno, de Mary Shelley (2017) pretende sugerir uma reflexão crítica e romper com os horizontes de expectativa do leitor, construindo um diálogo entre o contexto do leitor e o contexto do autor, ou até mesmo da 
própria obra (Jauss, 1994). É possível observar uma interação com o meio e lançar um leitor implícito inteligente, ou seja, o qual faz parte de uma estrutura textual, presente no momento da criação de determinada obra (Iser, 1999).

\section{A Narrativa de Frankenstein e o Ensino de Língua Inglesa}

A obra Frankenstein ou o Prometeu Moderno - Edição Comentada da Zahar (Shelley, 2017) está dividida em três volumes. O volume 1 tem 8 capítulos, o volume 2 possui 9 capítulos e o volume 3 conta com 7 capítulos. Mary Shelley realizou diversas modificações em Frankenstein ao longo do tempo. A primeira edição foi publicada anonimamente no ano de 1818 em três volumes, porém foi publicada uma segunda edição em 1823, já com o nome da autora e em dois volumes. Em 1831, foi publicada uma terceira edição de volume único. A editora Zahar (Shelley, 2017) se preocupou em manter a divisão dos três volumes originais, mas baseando-se na terceira edição, publicada no ano de 1831 .

No site da banca da CAPES, é possível encontrar 38 dissertações e 13 teses defendidas que discutem a obra de Mary Shelley nas áreas de Linguística, Letras e Humanas, bem como nas áreas de Ciências Biológicas, Sociais e Exatas (Catálogo de Teses e Dissertações, 2020).

Frankenstein (1818) é um dos romances mais conhecidos e importantes do gênero de horror e fantástico, juntamente com Drácula, de Bram Stoker (publicado em 1897). A história também é conhecida por ser adaptada para os cinemas. Sua primeira versão foi um curta-metragem de 16 minutos, orientado por J. Searle Dawley, em 1910 nos Estados Unidos. No entanto, a versão mais conhecida é a adaptação da Universal Pictures, em 1931, dirigida por James Whale e produzida por Carl Laemmle Jr. Mesmo que não tenha permanecido tão fiel à obra, esta é a versão em que lembramos quando pensamos na criatura de Frankenstein. Victor, seu nome no filme, se torna Henry Frankenstein, é interpretado pelo ator Colin Clive e o monstro é atuado por Boris Karloff. A duração do filme é de aproximadamente uma hora e 11 minutos.

Além dessas duas versões, muitas outras foram apresentadas ao público. Para dar continuidade à história, no ano de 1935, a Universal lançou “A noiva do Frankenstein”, visto o sucesso que o primeiro filme obteve. Na obra original de Mary Shelley, o criador, Victor é confrontado com a sua criação feminina para que ele passe seus dias mais alegres ao ter uma semelhante, depois de todo o preconceito que sofreu. No início, Victor consente, porém depois de refletir muito sobre o assunto, ele desiste da criação, pois tem medo de que ela se torne uma assassina igual a ele. Na versão de 1935, a Universal apresenta uma sequência para a história de Shelley e dá vida à criatura feminina. A atriz que interpreta a noiva de Frankenstein é Elsa Lanchester. Já no ano de 1939, a Universal aposta novamente em uma sequência para a história, apresentando "O filho de Frankenstein".

A história de Frankenstein ou o Prometeu Moderno se inicia com a troca de cartas do capitão Robert Walton com sua irmã, Sra. Margaret Saville. Ele conta em quatro cartas à irmã o quão solitário estava se sentindo a bordo, mesmo em companhia de outros homens. Ele afirma que gostaria de ter uma companhia masculina ao lado dele para que se sentisse melhor. Em uma segunda feira à noite, 31 de julho, um acidente aconteceu. $\mathrm{O}$ capitão e seus companheiros se viram cercados de gelo, bloqueando o navio por todos os lados, além de estarem envoltos em neblina. Depois das duas horas, a neblina se dissipou, ainda estavam cercados de gelo, levaram um susto com a imagem à sua frente. Uma charrete em um trenó, puxada por cães, estava próximo ao navio, e sentado no trenó estava uma criatura gigante. O gelo derreteu e liberou o navio, mas ficaram ancorados até o dia clarear. Os marinheiros avistaram um homem e pediram para que adentrassem ao navio. O capitão Walton foi se aproximando do homem misterioso e ele decidiu contar a história de sua criação.

A obra propõe ideias inovadoras para a época em que foi escrita como o galvanismo, ou seja, fenômeno relacionado com a geração de correntes elétricas em seres sem vida.

Importante destacar a relevância da obra para a época, na medida em que foi escrita por uma jovem de 19 anos oitocentista, 
(...) em um contexto em que a intolerância diante da capacidade intelectual da mulher era a pauta mais comum, aparecendo, neste cenário, o texto de Shelley se mostra como uma arma de crítica e subversão de ideias invasivos e monstruosos exaltando a habilidade revolucionária da figura da mulher escritora (Soares, 2015, p. 16).

Shelley, em um dos trechos da obra, também discute a questão do casamento arranjado, muito comum naquela época. O capitão Walton, terceiro narrador, comandante de um navio busca por uma passagem para atravessar o Polo Norte. É nesse local inóspito que ele encontra Victor Frankenstein à deriva no gelo estava relembrando de quando estava prestes a se casar com uma jovem russa rica, porém ela pediu a ele que a poupasse desse casamento:

Há alguns anos, ele amou uma jovem russa de fortuna modesta e, tendo reunido uma soma considerável em dotes, o pai da menina consentiu com o casamento. Ele viu a amada uma vez antes da fatídica cerimônia, mas ela estava banhada em lágrimas e, jogando-se aos pés dele, implorou-lhe que a poupasse, confessando amar outro, mas que este era pobre e seu pai nunca consentiria com a união (Shelley, 2017, p. 26-27).

A adaptação da obra Frankenstein por Margaret Tarner pela editora Macmillan composta no PNLD Literário 2018 traz questões importantíssimas sobre o lugar do monstro no mundo: o que é ser diferente e como se pode existir sendo uma criatura única no planeta, que a partir da estética da recepção possibilita mediar uma leitura construtiva de relevância para os alunos, além de um trabalho interdisciplinar.

É possível trazer a questão da solidão do monstro - que cobrará de seu criador a responsabilidade que tem sobre sua existência, mostrando-lhe as consequências perversas de seus atos- estabelecendo um paralelo com os dias atuais, que de certa forma estamos isolados socialmente e solitários por conta da pandemia.

As temáticas apresentadas na obra adaptada em inglês permitem explorar para além dos conhecimentos linguísticos do idioma trazendo à discussão temas próximos dos alunos. No capítulo 1 "I go to University" o médico se apresenta falando de sua família, da sua terra natal e dos anseios de sua mãe para que ele frequentasse a universidade. Já no capítulo 2 "The secret of life" iniciam-se os questionamentos de Frankenstein sobre a vida e a morte "What was the difference between a living person and a dead body? Why did a dead body turn to dust? Could a dead man come alive again?”.

A obra adaptada se enquadra no nível A1 do Quadro Europeu Comum de Referência para Línguas (Common European Framework of Reference for Languages - CEFR) que é um padrão internacionalmente reconhecido para descrever a proficiência em um idioma. Segundo o Conselho Britânico, no nível A1 do CEFR:

“...espera-se que o aluno seja capaz de compreender e usar expressões familiares e cotidianas, assim como enunciados muito simples, que visam satisfazer necessidades concretas. Pode apresentar-se e apresentar outros e é capaz de fazer perguntas e dar respostas sobre aspectos pessoais como, por exemplo, o local onde vive, as pessoas que conhece e as coisas que têm. Pode comunicar de modo simples, se o interlocutor falar lenta e distintamente e se mostrar cooperante".

Nesta perspectiva, ressalta-se a importância do papel do professor mediador no processo de leitura para que o aluno não fique limitado a compreensão do texto por questões linguísticas.

Para Barbosa (1996) o ensino da literatura se situa entre a leitura e a crítica, razão pela qual é sempre bom termos em mente o que seja a leitura e o que seja a crítica, o autor ainda acrescenta que o ensino da literatura decorre da experiência da leitura entendida como:

um processo de concretização daquilo que, no poema, era abstração da linguagem. Entre a experiência do poeta (...), que tende à abstração por força da linguagem que a realiza, e a experiência de leitura, que força a concretização, o leitor e o texto interagem entre sons e sentidos que se fazem e refazem de modo ininterrupto. (1996, p. 64-65) 
Entendemos que na relação entre a literatura e o ensino, a figura do mediador é fundamental, vez que há um espaço profundo e imenso obstáculo a ser enfrentado por todos aqueles que se interessam pela reflexão sobre o trabalho de mediação de leitura no contexto escolar.

A linguagem da arte literária acolhe e possibilita, nos intervalos de um gesto abstrato, a experiência concreta, vivida pelo leitor. Contudo, essa experiência implica uma etapa de aprendizagem onde inicia o trabalho de mediação entre o leitor e a obra.

\section{Conclusão}

Este artigo buscou apresentar uma análise da obra Frankenstein ou O Prometeu moderno (1818) da escritora Mary Shelley, a partir da edição em português pela Zahar, publicada no ano de 2017.

A pesquisa mostrou por meio do aporte teórico da Estética da Recepção e do Efeito (Jauss, 1994; Iser, 1996 e 1999) e (Bittencourt, 2008), que é possível trabalhar nas aulas de língua e literatura inglesa com textos literários explorando temáticas que contribuem para a construção do leitor estético na sala de aula.

A obra possui discurso emancipatório, por se tratar de uma obra de autoria feminina, considerada um clássico universal. Assim, pretendemos sugerir uma reflexão crítica e um rompimento com os horizontes de expectativa do leitor, construindo um diálogo entre o contexto do leitor e o contexto do autor, ou até mesmo da própria obra (Jauss, 1994).

Nesta perspectiva, é possível afirmar, com a pesquisa, que a obra Frankenstein ou O Prometeu moderno (1818), da escritora Mary Shelley, possui temáticas relevantes para o trabalho em sala de aula com alunos do ensino médio. Dessa forma, o ensino da língua inglesa por meio da adaptação da obra Frankenstein apresenta um universo vasto de possibilidades de conhecimentos para além da aquisição de repertório linguístico.

Trata-se de um trabalho que possui relevância social, na medida em que disponibiliza para os professores de língua inglesa um estudo sobre as diretrizes e teóricos, no que diz respeito ao ensino de língua inglesa por meio de texto literário.

O desenvolvimento do trabalho evidencia que o tema, ensino de língua estrangeira a partir do texto literário Frankenstein da escritora Mary Shelley, estudado por diversos autores, mostra a complexidade do tema na medida em que apresenta várias perspectivas de práticas de ensino que atenda a todos os contextos e todas as necessidades dos alunos. Neste sentido, o tema da pesquisa continua válido para aprofundamento em estudos futuros.

\section{Referências}

Barbosa, J. A. (1994). Literatura nunca é apenas literatura. Depoimento apresentado no Seminário Linguagem e Linguagens: a fala, a escrita, a imagem. Série Ideias n.17. FDE. Centro de Referência Mario Covas.

Bittencourt, C. M. F. (2008). Ensino de História: fundamentos e métodos. 2ed. Cortez

Bonicci, T. (2007). Teoria e crítica literária feminista: conceitos e tendências. Maringá, PR: Eduem.

Brasil. Ministério da Educação. Decreto n. 9.099, de 18 de julho de 2017. Dispõe sobre o Programa Nacional do Livro e do Material Didático.

Brasil. Ministério da Educação. PNLD 2018: literário / Ministério da Educação - Secretária de Educação Básica - SEB - Fundo Nacional de Desenvolvimento da Educação. Brasília, DF.

Brasil. Ministério da Educação. (1998). Parâmetros Curriculares Nacionais. Língua Estrangeira. Brasília.

Brasil. Ministério da Educação. (2018). Base Nacional Comum Curricular. Brasília.

Calvino, I. (1993). Por que ler os clássicos. Tradução, O Nilson Moulin. - São Paulo: Companhia das Letras.

Candido, A. (2002). A literatura e a formação do homem. In:__. Textos de intervenção. Seleção, apresentação e notas Vinicius Dantas. Coleção Espírito Crítico. São Paulo: Ed. 34.

Catálogo de Teses e Dissertações. https://catalogodeteses.capes.gov.br/catalogo-teses/\#!/. 
Research, Society and Development, v. 10, n. 7, e58710716960, 2021

(CC BY 4.0) | ISSN 2525-3409 | DOI: http://dx.doi.org/10.33448/rsd-v10i7.16960

Collie, J.\& Slater, S. (1987). Literature in the language classroom: a resource book of ideas and activities. Cambridge: Cambridge University Press.

Colomer, T. (2003). A formação do leitor literário: narrativa infantil e juvenil atual. Trad. Laura Sandroni. São Paulo: Global.

Eagleton, T. (1997). Teoria da literatura: uma introdução. 3 ed. rev. ampl. São Paulo: Martins Fontes.

Eco, U. (1985). Pós-escrito a O nome da Rosa: as origens e o processo de criação do livro mais vendido em 1984. Trad. Letizia Zini Antunes e Alvaro Lorencini. 2. Ed. Rio de Janeiro: Nova Fronteira.

Esser, D. C. (2014). Literatura de autoria feminina - mulheres em cena, na história e na memória. Revista Línguas \& Letras, Cascavel, v. 15, n. 30, p. 1-18.

Gomes, G. A. (2007). O Mentor das Brasileiras: um estudo de caso. Virtual, Revista eletrônica do ICHL/UFJF, v.6, p.7, p.10.

Iser, W. (1996). O ato da leitura: uma teoria do efeito estético. Trad. Johannes Kretschmer. São Paulo: Ed. 34.

Jauss, H. R. (1979). A estética da recepção: colocações gerais. In: LIMA, Luiz Costa. A Literatura e o leitor: textos de estéticas da recepção. Rio de Janeiro: Paz e Terra, p. $43-61$.

La Rocque, L.; Teixeira, L.A. (2001) Frankenstein, de Mary Shelley e Drácula, de Bram Stoker: gênero e ciência na literatura. Hist Cienc Saude Manguinhos p.10-34.

Lima, L. C. (1979). Que significa a recepção dos textos ficcionais. A Literatura e o leitor: textos de estéticas da recepção. Rio de Janeiro: Paz e Terra, p. 119 $-171$.

Magalhães, I. A. (1992). Os véus de Ártemis: alguns traços da ficção narrativa de autoria feminina. Revista Colóquio Letras nº 125 e nº 126 , p.151-168.

Miskolci, R. (2011). Frankenstein e o Espectro do Desejo. In: cadernos Pagu. Campinas: Núcleo de Estudos de Gênero Pagu-UNICAMP.

Soares, J. P. (2015). Frankenstein e a monstruosidade das intenções: A criatura como representação da condição feminina. 2015.142 f. Dissertação (Mestrado) - Curso de Letras, Universidade Federal da Paraíba, João Pessoa.

Severino, A. J. (2007). Metodologia do trabalho científico. 23. ed. rev. e atual. São Paulo: Cortez.

Shelley, M. (2017). Frankenstein ou o Prometeu Moderno. Trad. Santiago Nazarian. - 1.ed. - Rio de Janeiro: Zahar.

Stierle, K. (1979). Que significa a recepção dos textos ficcionais. In: LIMA, Luiz Costa. A Literatura e o leitor: textos de estéticas da recepção. Rio de Janeiro: Paz e Terra. p. 119 - 171 